\title{
HUBUNGAN PENGETAHUAN DAN SIKAP DENGAN PENGGUNAAN ALAT PELINDUNG DIRI (APD) PADA TENAGA KERJA BAGIAN JARING
}

\author{
Endang Nur Amaludin* Suzana Indragiri**
}

\begin{abstract}
ABSTRAK
Sumberdaya manusia sebagai tenaga kerja tidak lepas dari masalah-masalah yang berkaitan dengan keselamatan dalam bekerja yang langsung berhubungan dengan peralatan dan mesin untuk menunjang proses produksi. Penggunaan berbagai alat dan mesin ini menyebabkan tenaga kerja tidak akan terlepas dari resiko yang menyangkut keselamatan dan kesehatan kerja. Risiko ini dapat menimpa tenaga kerja kapan dan dimana saja, sehingga membutuhkan perhatian khusus dari berbagai pihak yang berkaitan seperti pengusaha, tenaga kerja dan perusahaan. Perusahaan yang mempekerjakan tenaga kerja dan mempunyai potensi bahaya yang ditimbulkan oleh proses produksi yang dapat mengakibatkan kecelakaan kerja seperti peledakan, kebakaran, pencemaran dan penyakit akibat kerja, wajib menerapkan keselamatan dan kesehatan kerja. Penelitian ini bertujuan untuk mengetahui hubungan pengetahuan dan sikap dengan penggunaan APD pada tenaga kerja bagian jaring di PT. Arteria Daya Mulia (ARIDA) Cirebon. Metode penelitian yang dilakukan adalah deskriptif analitik dengan pendekatan yang bersifat studi cross sectional. Populasi dalam penelitian ini adalah seluruh tenaga kerja bagian jaring sebanyak 222 tenaga kerja, jumlah sample 89 tenaga kerja yang dipilih berdasarkan metode proporsional random sampling. Pengumpulan data dilakukan dengan pengisian kuesioner, metode pengolahan data dengan menggunakan wawancara analisa data dengan menggunakan uji statistik. Hasil penelitian menunjukan bahwa berdasarkan uji statistik (Chi-Square) menunjukan bahwa tidak ada hubungan antara pengetahuan dengan penggunaan alat pelindung diri (APD) nilai $P$ value $=0,946$, dan ada hubungan antara sikap dengan penggunaan alat pelindung diri (APD) nilai $P$ value $=0,000$, pada tenaga kerja bagian jaring PT. Arteria Daya Mulia (ARIDA) Cirebon Tahun 2016.
\end{abstract}

Kata Kunci : Pengetahuan, sikap, penggunaan alat pelindung diri

\begin{abstract}
Human resources as labor can not be separated from issues relating to safety in work directly related to the equipment and machinery to support the production process. The use of various tools and machinery have led to labor will not be separated from the risks relating to occupational safety and health. This risk can override the workforce anytime and anywhere, thus requiring special attention from various parties associated as employers, labor and business. Companies that employ workers and have the potential dangers posed by the production process that can cause accidents such as explosions, fires, pollution and occupational diseases, shall implement occupational safety and health. This study aims to determine the relationship of knowledge and attitudes to the use of PPE in the labor section nets in PT. Arteria Daya Mulia (ARIDA) Cirebon. The research method is descriptive analytic approach that is both cross-sectional study. The population in this study is a part of the net the entire workforce of 222 workers, the number of workers 89 samples were selected based on proportional random sampling method. Data were collected by questionnaires, data processing method using interview data analysis using statistical tests. The results showed that, based on statistical tests (Chi-Square) shows that there is no relation between knowledge and the use of personal protective equipment (PPE) P value $=0.946$, and there is a relationship between attitudes to the use of personal protective equipment (PPE) $\mathrm{P}$ value $=0,000$, the labor section nets PT. Arteria Daya Mulia (ARIDA) Cirebon 2016.
\end{abstract}

Keywords : knowledge, attitude, use of personal protective equipment

\footnotetext{
* Alumni PSKM STIKes Cirebon Lulus Tahun 2016

** Staf Pengajar Program Studi S1 Kesehatan Masyarakat STIKes Cirebon
} 


\section{PENDAHULUAN}

Di era globalisasi dan pasar bebas World Trade Organization (WTO) yang akan berlaku tahun 2020 mendatang, keselamatan dan kesehatan kerja merupakan salah satu prasyarat yang ditetapkan dalam hubungan ekonomi perdagangan barang dan jasa antar negara yang harus dipenuhi oleh seluruh negara anggota, termasuk bangsa Indonesia. ${ }^{1}$

Perusahaan yang mempekerjakan tenaga kerja dan mempunyai potensi bahaya yang ditimbulkan oleh proses produksi yang dapat mengakibatkan kecelakaan kerja seperti peledakan, kebakaran, pencemaran dan penyakit akibat kerja, wajib menerapkan keselamatan dan kesehatan kerja. Berdasarkan PERMNAKER 05/MEN/1996 dan mengacu pada undangundang No. 1 tahun 1970 tentang keselamatan dan kesehatan kerja, perlindungan tenaga kerja dari bahaya kecelakaan dan penyakit akibat kerja maupun akibat lingkungan kerja. ${ }^{2}$

Berdasarkan data dari Internasional Labour Organization (ILO) tahun 2015 mencatat, setiap hari terjadi sekitar 6000 kecelakaan, kecelakaan kerja mengakibatkan korban fatal di dunia. Di Indonesia, ada 20 kasus kecelakaan dialami para buruh dari setiap 100 ribu tenaga kerja, dan 30 persen terjadi sektor kontruksi. ${ }^{3}$

Angka kecelakaan kerja di Indonesia masih tinggi. Mengutip dari data Badan Penyelenggara Jaminan Sosial Ketenagakerjaan hingga akhir 2015 telah terjadi kecelakaan kerja sebanyak 105.182 kasus. Sementara untuk kasus kecelakaan berat yang mengakibatkan kematian tercatat sebanyak 2.375 kasus dari total jumlah kecelakaan kerja. ${ }^{3}$

Berdasarkan data laporan kecelakaan kerja dari dinas tenaga kerja dan transmigrasi (Disnakertrans) Kabupaten Cirebon pada tahun 2014 tercatat terjadi kasus kecelakaan kerja dengan korban meninggal 4 orang, 11 orang luka ringan, 185 orang luka sedang dan luka berat 10 orang. ${ }^{4}$

Hal terbesar yang menjadi penyebab kecelakaan kerja yaitu perilaku yang tidak aman dan kondisi lingkungan yang tidak aman, berdasarkan data dari Biro Pelatihan Tenaga Kerja (BPTK), penyebab kecelakaan yang sering terjadi sampai saat ini diakibatkan oleh perilaku yang tidak aman, antara lain disebabkan tidak hati-hati, tidak mematuhi peraturan, tidak mengikuti standar prosedur kerja, tidak memakai Alat Pelindung Diri (APD) dan kondisi badan yang lemah.

Efisiensi dan efektivitas kerja karyawan dapat dicapai dengan meningkatkan pengetahuan karyawan, keahlian karyawan, dan sikap karyawan terhadap tugas-tugasnya. Dengan adanya peningkatan pengetahuan, keahlian dan sikap terhadap tugas maka diharapkan akan mengubah perilaku guna mendapatkan produktivitas yang tinggi. ${ }^{5}$

Penggunaan alat pelindung diri merupakan tahap terakhir dari metode pengendalian kecelakaan maupun penyakit akibat kerja. Meskipun demikian, penggunaan alat pelindung diri akan menjadi sangat penting apabila pengendalian secara teknis dan administrasi telah dilakukan secara maksimal namun potensi tergolong tinggi. Besarnya manfaat dari penggunaan alat pelindung diri ini pada saat bekerja tidak menjamin semua pekerja akan memakai karena ternyata masih banyak pekerja juga yang tidak menggunakannya. Alat pelindung diri sudah lazim digunakan oleh pekerja namun pada kenyataan belum semua pekerja menggunakan sebagaimana seharusnya. Keefektifan penggunaan alat pelindung diri adalah terbentur dari tenaga kerja sendiri. Banyak faktor yang mempengaruhi perilaku pekerja sehingga tidak menggunakan alat pelindung diri yang telah disediakan oleh perusahaan antara lain kedisiplinan dalam menggunakan alat pelindung diri selain itu juga sikap tenaga kerja yang masih merasa tidak nyaman dalam menggunakan alat pelindung diri (APD). Dengan menggunakan alat pelindung diri (APD) pada waktu bekerja maka kemungkinan untuk terjadi kecelakaan menjadi kecil. Oleh karena itu alat pelindung diri (APD) harus diperhatikan oleh semuanya baik oleh tenaga kerja maupun oleh perusahaan. ${ }^{6}$ 
Tujuan penelitian ini adalah ingin mengetahui hubungan pengetahuan dan sikap dengan penggunaan APD pada tenaga kerja bagian jaring di PT. Arteria Daya Mulia (ARIDA) Cirebon.

\section{METODE PENELITIAN}

Penelitian ini merupakan penelitian penjelasan (Explanatory Research) menggunakan metode survey dengan pendekatan cross-sectional. Variabel independennya adalah pengetahuan dan sikap, dan variabel dependennya adalah penggunaan alat pelindung diri. Populasi dalam penelitian ini adalah seluruh tenaga kerja bagian jaring di PT. Arteria Daya Mulia (ARIDA) Cirebon sebanyak 222 tenaga kerja diambil dari data pada bulan Juni tahun 2016. Pengambilan sample dengan Proporsional random sampling dan didapatkan jumlah sampel sebesar 89 responden.

\section{HASIL PENELITIAN \\ Analisis Univariat \\ Pengetahuan}

Tabel 1. Distribusi frekuensi responden berdasarkan pengetahuan tentang penggunaan alat pelindung diri

\begin{tabular}{|c|c|c|}
\hline Pengetahuan & Frekuensi & Persentase $(\%)$ \\
\hline Kurang Baik & 50 & 56,2 \\
\hline Baik & 39 & 43,8 \\
\hline Jumlah & 89 & 100 \\
\hline
\end{tabular}

Berdasarkan tabel 1 dapat diketahui bahwa sebanyak 56,2\% responden memiliki pengetahuan yang kurang baik tentang penggunaan alat pelindung diri.

\section{Sikap}

Tabel 2. Distribusi frekuensi responden berdasarkan sikap tentang penggunaan alat pelindung diri

\begin{tabular}{|c|c|c|}
\hline Sikap & Frekuensi & Persentase $(\%)$ \\
\hline Kurang Baik & 48 & 53,9 \\
\hline Baik & 41 & 46,1 \\
\hline Jumlah & 89 & 100 \\
\hline
\end{tabular}

Berdasarkan tabel 2 dapat diketahui bahwa sebanyak 53,9\% responden memiliki sikap yang kurang baik tentang penggunaan alat pelindung diri.

\section{Penggunaan Alat Pelindung Diri (APD)}

Tabel 3. Distribusi frekuensi responden berdasarkan penggunaan alat pelindung diri

\begin{tabular}{lcc}
\hline \multicolumn{1}{c}{ Penggunaan Alat } & Frekuensi & Persentase (\%) \\
\hline Pelindung Diri & 46 & 51,7 \\
Tidak Menggunakan & 43 & 48,3 \\
\hline Menggunakan & 89 & 100 \\
\hline
\end{tabular}


Berdasarkan tabel 3 dapat diketahui bahwa sebanyak 51,7\% responden tidak menggunakan alat pelindung diri pada saat melakukan pekerjaan.

\section{Analisis Bivariat}

\section{Hubungan Antara Pengetahuan Dengan Penggunaan Alat Pelindung Diri}

Tabel 4. Hubungan Antara Pengetahuan Dengan Penggunaan Alat Pelindung Diri

\begin{tabular}{|c|c|c|c|c|c|c|c|}
\hline \multirow{3}{*}{ Pengetahuan } & \multicolumn{4}{|c|}{ Penggunaan Alat Pelindung Diri } & \multicolumn{2}{|c|}{ Jumlah } & \multirow{3}{*}{$p$ value } \\
\hline & \multicolumn{2}{|c|}{$\begin{array}{c}\text { Tidak } \\
\text { Menggunakan }\end{array}$} & \multicolumn{2}{|c|}{ Menggunakan } & \multirow[t]{2}{*}{$\mathrm{n}$} & \multirow[t]{2}{*}{$\%$} & \\
\hline & $\mathrm{n}$ & $\%$ & $\mathrm{n}$ & $\%$ & & & \\
\hline Kurang Baik & 26 & 52,0 & 24 & 48,0 & 50 & 100 & \\
\hline Baik & 20 & 51,3 & 19 & 48,7 & 39 & 100 & 0,946 \\
\hline Total & 46 & 51,7 & 43 & 48,3 & 89 & 100 & \\
\hline
\end{tabular}

Dari hasil uji statistik dengan menggunakan uji chi square didapatkan nilai $p$ value $=$ 0,946 hal ini menunjukan tidak ada hubungan yang bermakna antara pengetahuan dengan penggunaan alat pelindung diri pada tenaga kerja bagian jaring di PT. Arteria Daya Mulia (ARIDA) Cirebon tahun 2016.

\section{Hubungan Antara Sikap Dengan Penggunaan Alat Pelindung Diri}

Tabel 5. Hubungan Antara Sikap Dengan Penggunaan Alat Pelindung Diri

\begin{tabular}{|c|c|c|c|c|c|c|c|}
\hline \multirow{3}{*}{ Sikap } & \multicolumn{4}{|c|}{ Penggunaan Alat Pelindung Diri } & \multicolumn{2}{|c|}{ Jumlah } & \multirow{3}{*}{$p$ value } \\
\hline & \multicolumn{2}{|c|}{$\begin{array}{c}\text { Tidak } \\
\text { Menggunakan }\end{array}$} & \multicolumn{2}{|c|}{ Menggunakan } & \multirow[t]{2}{*}{$\mathrm{n}$} & \multirow[t]{2}{*}{$\%$} & \\
\hline & $\mathrm{n}$ & $\%$ & $\mathrm{n}$ & $\%$ & & & \\
\hline Kurang Baik & 40 & 83,3 & 8 & 16,7 & 48 & 100 & 0000 \\
\hline Baik & 6 & 14,6 & 35 & 85,4 & 41 & 100 & 0,000 \\
\hline Total & 46 & 51,7 & 43 & 48,3 & 89 & 100 & \\
\hline
\end{tabular}

Dari hasil uji statistik dengan menggunakan uji chi square didapatkan nilai $p$ value $=$ 0,000 hal ini menunjukan ada hubungan yang bermakna antara sikap dengan penggunaan alat pelindung diri pada tenaga kerja bagian jaring di PT. Arteria Daya Mulia (ARIDA) Cirebon tahun 2016.

\section{PEMBAHASAN}

\section{Hubungan Antara Pengetahuan Dengan Penggunaan Alat Pelindung Diri}

Berdasarkan hasil penelitian diketahui bahwa tidak ada hubungan pengetahuan dengan penggunaan alat pelindung diri pada tenaga kerja bagian jaring di Arteria Daya Mulia (ARIDA) Cirebon. Hasil ini didasarkan pada uji statistik diperoleh p-value sebesar 0,946.

Pengetahuan merupakan hasil dari tahu dan ini terjadi setelah seseorang melakukan penginderaan terhadap objek. Penginderaan terjadi melalui panca indera manusia, yakni indera penglihatan, pendengaran, penciuman, rasa dan raba. Sebagian besar pengetahuan manusia diperoleh melalui mata dan telinga. ${ }^{7}$

Berdasarkan analisa peneliti tingkat pengetahuan tenaga kerja di PT. Arteria Daya Mulia (ARIDA) bagian jaring merupakan hasil dari tahu artinya sebagai pengingat suatu materi atau 
objek yang telah dipelajari sebelumnya tentang manfaat dan dampak dari penggunaan alat pelindung diri, memahami artinya sebagai suatu kemampuan untuk menjelaskan secara benar tentang objek yang diketahui seperti manfaat dan dampak dari penggunaan alat pelindung diri dan tenaga kerja belum dapat mengaplikasi, menganalisis, sintesis dan mengevaluasi terhadap suatu materi atau objek yang diterima,berdasarkan dari 6 cakupan tingkatan pengetahuan.

Hasil penelitian ini sejalan dengan hasil penelitian yang dilakukan oleh Afin Anete Rafi (2014) yang menyatakan bahwa tidak ada hubungan antara pengetahuan dalam penggunaan alat pelindung diri (APD). ${ }^{8}$ Hasil tersebut didukung oleh penelitian Muhammad Nur Sohib (2013) yang menyatakan bahwa tidak ada hubungan antara pengetahuan dalam penggunaan alat pelindung diri. ${ }^{9}$ Hasil tersebut didukung pula oleh Rahwan Ahmad (2012) yang menyatakan bahwa tidak ada hubungan antara pengetahuan dalam penggunaan Alat Pelindung Diri (APD). ${ }^{10}$

\section{Hubungan Antara Sikap Dengan Penggunaan Alat Pelindung Diri}

Berdasarkan hasil penelitian diketahui bahwa ada hubungan sikap dengan penggunaan alat pelindung diri pada tenaga kerja bagian jaring di Arteria Daya Mulia (ARIDA) Cirebon. Hasil ini didasarkan pada uji statistik diperoleh $p$-value sebesar 0,000.

Sikap adalah reaksi atau respon yang masih tertutup dari seseorang terhadap suatu stimulus atau objek. $^{11}$ Menurut Kirscht dalam Green. L menyebutkan bahwa sikap menggambarkan suatu kumpulan keyakinan yang selalu mencakup aspek evaluatif sehingga sikap selalu dapat diukur dalam bentuk baik dan buruk atau positif dan negative. ${ }^{12}$

Hasil penelitian ini sejalan dengan hasil penelitian yang dilakukan oleh Afin Anete Rafi (2014) yang menyatakan bahwa ada hubungan antara sikap dalam penggunaan alat pelindung diri (APD). ${ }^{8}$ Hasil tersebut didukung oleh penelitian Ilham Novriandi (2013) yang menyatakan bahwa ada hubungan antara sikap dalam penggunaan alat pelindung diri (APD). ${ }^{13}$

\section{SIMPULAN}

1. Tidak ada hubungan antara pengetahuan dengan penggunaan alat pelindung diri pada tenaga kerja bagian jaring di PT. Arteria Daya Mulia (ARIDA) Cirebon Tahun 2016.

2. Ada hubungan antara sikap dengan penggunaan alat pelindung diri pada tenaga kerja bagian jaring di PT. Arteria Daya Mulia (ARIDA) Cirebon Tahun 2016.

\section{SARAN}

\section{Saran Teoritis}

1. Untuk Peneliti

Perlu dilakukan penelitian lebih lanjut dengan menambahkan variabel seperti pengawasan, kebijakan, dengan waktu penelitian yang lebih lama agar mendapatkan hasil yang maksimal.

2. Untuk STIKes Cirebon

Hasil penelitian ini perlu dikembangkan dan dijadikan sebagai salah satu sumber untuk pengembangan ilmu dan pengetahuan tentang penggunaan Alat Pelindung Diri (APD) yang lebih dalam sehingga dapat berguna khususnya bagi mahasiswa dan pembaca lainnya sebagai bahan pertimbangan bagi penelitian lain yang lebih luas.

\section{Saran Praktis}

1. Untuk PT. Arteria Daya Mulia (ARIDA) Cirebon

1) Meningkatkan program pelatihan tentang penggunaan alat pelindung diri bagi tenaga kerja.

2) Meningkatkan sosialisasi kepada tenaga kerja tentang penggunaan alat pelindung diri.

3) Meningkatkan pengawasan terhadap tenaga kerja agar tenaga kerja dapat menggunakan alat pelindung diri pada saat bekerja. 
4) Sebaiknya peraturan yang ada lebih dipertegas lagi dengan berlakunya sanksi dan penghargaan agar dapat memberikan motivasi terhadap tenaga kerja.

2. Untuk Tenaga Kerja PT. Arteria Daya Mulia (ARIDA) Cirebon

1) Bekerja sesuai dengan standar operasional prosedur yang telah ditetapkan oleh perusahaan.

2) Patuhi peraturan perusahaan tentang penggunaan alat pelindung diri.

3) Selalu menggunakan alat pelindung diri pada saat bekerja.

\section{DAFTAR PUSTAKA}

1. Winarso Arso. Artikel Tentang Keselamatan Kerja; [diakses tanggal 07 April 2015]. Diunduh dari http://budayasafety.blogspot.com/2013/10/artikel-tentang-keselamatankerja-k3.html.

2. Fatahuddino. Pengaruh Program Keselamatan dan Kesehatan Kerja Terhadap Kepuasan Kerja Karyawan PT. PLN PLTU Barru; [diakses tanggal 11 Juni 2015]. Diunduh dari : http://fatahuddino5.blogspot.com/2014/10/proposal-skripsi.html.

3. Analisis Kecelakaan Kerja (diakses pada 16 Maret 2016) Diunduh dari :http//katigaku.com.2015/06/04analisis-kecelakaankerja.

4. Amelia Hutasoit.Data Kecelakaan Kerja 2014. [diakses pada tanggal 16 Maret 2016]. Diunduh dari http//www.depkes.go.id/article/view/20141030001 oranpekerjadiduniameninggalsetiap15d etikkarenakecekaankerja.html\#stash.VagKwLZM.dpuf

5. Sucipto, Cecep Dani. Keselamatan dan Kesehatan Kerja. Yogyakarta: Gosyen Publishing;2014

6. Lila Nur Azkia Amaeta. Hubungan Pengetahuan dan Sikap dengan Perilaku Pertolongan Pertama Pada Kecelakaan (P3K) Pada Karyawan Sub Departemen Warehouse PT. Japfa Comfeed Indonesia Tbk. Unit Cirebon Tahun 2015. Skripsi. Cirebon. Program Studi Kesehatan Masyarakat STIKes Cirebon;2015

7. Soekidjo Notoatmodjo. Kesehatan Masyarakat Ilmu dan Seni. Jakarta. Rineka Cipta; 2011.

8. Afni Anete Refi. Hubungan Antara Pengetahuan dan Sikap Dengan Tindakan Penggunaan Alat Pelindung Diri Pada Tenaga Kerja di PT. Tropica Cocoprima Desa Lelema Kecamatan Tumpaan Kabupaten Minahasa Selatan. Skripsi. FKM Sam Ratulangi;2015

9. Muhammad Nur Sohib. Hubungan Antara Pengetahuan dan Sikap Dengan Praktek Pemakaian (APD) Pada Petani Pengguna Pestisida Di Desa Curut Kecamatan Panawangan Kabupaten Grobogan. Skripsi: Semarang; Fakultas Kesehatan Universitas Dian Nuswantoro Semarang; 2013.

10. Rahwan Ahmad. Hubungan Pengetahuan dan Sikap Karyawan Dengan Penggunaan Alat Pelindung Diri (APD) PT. Harta Samudra Pelabuhan Perikanan Nusantara Ambon. Skripsi: Universitas Gorontalo;2012.

11. Widodo, A. Profil Pertanyaan Guru dan Siswa dalam Pembelajaran Sains. The Feature of Teacher and Students Question In The Sciens. Jurnal 4(2), 139-148. Bandung: Jurusan Pendidikan Biologi FPMIPA UPI;2006

12. Ahmadi. Psikologi Belajar. Jakarta: Rineka Cipta; 2014

13. Ilham Noviandry. Faktor-faktor yang Berhubungan Dengan Perilaku Pekerja dalam Penggunaan Alat Pelindung Diri (APD) Pada Industri Pengelasan Informal di Kelurahan Gondrong Kecamatan Cipondoh Kota Tangerang. Skripsi. Jakarta: Program Studi Kesehatan Masyarakat Fakultas Kedokteran dan Ilmu Kesehatan UIN Syarif Hidayatullah Jakarta; 2013 